\title{
A Laboratory-Scale Study of the Applicability of a Halophilic Sediment Bioelectrochemical System for in situ Reclamation of Water and Sediment in Brackish Aquaculture Ponds: Effects of Operational Conditions on Performance ${ }^{\mathbb{S}}$
}

\author{
Hai The Pham ${ }^{1,2 *}$, Phuong Ha Vu', Thuy Thu Thi Nguyen ${ }^{1}$, Ha Viet Thi Bui ${ }^{2}$, Huyen Thanh Thi Tran ${ }^{2}$, \\ Hanh My Tran ${ }^{2}$, Huy Quang Nguyen ${ }^{3}$, and Byung Hong Kim ${ }^{4}$ \\ ${ }^{1}$ Research group for Physiology and Applications of Microorganisms (PHAM group), GREENLAB, Center for Life Science Research \\ (CELIFE), Faculty of Biology, Vietnam National University in Hanoi - University of Science, Hanoi, Vietnam \\ ${ }^{2}$ Department of Microbiology and ${ }^{3}$ Department of Biochemistry and Molecular Biology, Faculty of Biology, Vietnam National University in \\ Hanoi - University of Science, Hanoi, Vietnam \\ ${ }^{4}$ Korea Institute of Science and Technology, Seoul 02792, Republic of Korea
}

\author{
Received: June 29, 2019 \\ Revised: August 28, 2019 \\ Accepted: August 29, 2019 \\ First published online \\ September 2, 2019 \\ *Corresponding author \\ Phone: +84-943-318-978; \\ E-mail: phamthehai@vnu.edu.vn
}

$\mathrm{S}$ upplementary data for this paper are available on-line only at http://jmb.or.kr.

pISSN 1017-7825, eISSN 1738-8872

Copyright(C) 2019 by

The Korean Society for Microbiology and Biotechnology
Sediment bioelectrochemical systems (SBESs) can be integrated into brackish aquaculture ponds for in-situ bioremediation of the pond water and sediment. Such an in-situ system offers advantages including reduced treatment cost, reusability and simple handling. In order to realize such an application potential of the SBES, in this laboratory-scale study we investigated the effect of several controllable and uncontrollable operational factors on the in-situ bioremediation performance of a tank model of a brackish aquaculture pond, into which a SBES was integrated, in comparison with a natural degradation control model. The performance was evaluated in terms of electricity generation by the SBES, Chemical oxygen demand (COD) removal and nitrogen removal of both the tank water and the tank sediment. Real-life conditions of the operational parameters were also experimented to understand the most close-to-practice responses of the system to their changes. Predictable effects of controllable parameters including external resistance and electrode spacing, similar to those reported previously for the BESs, were shown by the results but exceptions were observed. Accordingly, while increasing the electrode spacing reduced the current densities but generally improved COD and nitrogen removal, increasing the external resistance could result in decreased COD removal but also increased nitrogen removal and decreased current densities. However, maximum electricity generation and COD removal efficiency difference of the SBES (versus the control) could be reached with an external resistance of $100 \Omega$, not with the lowest one of $10 \Omega$. The effects of uncontrollable parameters such as ambient temperature, salinity and $\mathrm{pH}$ of the pond (tank) water were rather unpredictable. Temperatures higher than $35^{\circ} \mathrm{C}$ seemed to have more accelaration effect on natural degradation than on bioelectrochemical processes. Changing salinity seriously changed the electricity generation but did not clearly affect the bioremediation performance of the SBES, although at $2.5 \%$ salinity the SBES displayed a significantly more efficient removal of nitrogen in the water, compared to the control. Variation of $\mathrm{pH}$ to practically extreme levels (5.5 and 8.8) led to increased electricity generations but poorer performances of the SBES (vs. the control) in removing COD and nitrogen. Altogether, the results suggest some distinct responses of the SBES under brackish conditions and imply that COD removal and nitrogen removal in the system are not completely linked to bioelectrochemical processes but electrochemically enriched bacteria can still perform nonbioelectrochemical COD and nitrogen removals more efficiently than natural ones. The results confirm the application potential of the SBES in brackish aquaculture bioremediation and help propose efficient practices to warrant the success of such application in real-life scenarios.

Keywords: Sediment bioelectrochemical systems, brackish aquaculture, in situ bioremediation, operational conditions 


\section{Introduction}

Aquaculture industry has become an important economic sector in many countries, as the result of increasing demands of human population for more and diverse food. Therefore, the aquaculture farmers are under huge pressures to increase their productivity. As the consequence, intensive rearing practices with huge daily feed loads into rearing ponds are more and more applied. By doing this, the aquaculturists have to face a number of problems relating to uneaten feed and excessive waste produced by fish or shrimp, because the accumulation of these materials can cause elevations in the levels of total nitrogen and organic matter in the pond water and sediment [1]. A pond environment with such elevated nitrogen and organic matter levels is favorable for microorganisms, including numerous pathogens, to grow. Resulted diseases can seriously reduce productivity, leading to heavy losses for aquaculturists. Furthermore, pollution of the water bodies receiving discharged water from such ponds is another serious threat [2]. It is therefore essential and urgent to develop measures to reduce feedrelated water pollution in aquaculture ponds.

A number of technologies for the reduction of water pollution in aquaculture ponds have been reported, including the use of artificial aeration systems and/or separate systems to treat and recycle the water, etc. [3]. Those technologies, although having high treatment efficiencies, were not cost-competitive because of their constructional and operational costs and energy expenses [1]. A new technology based on the use of a sediment bioelectrochemical system (SBES) (or benthic bioelectrochemical system) has been lately shown to be a promising solution for in situ reclamation of the water quality of aquaculture ponds [1,4]. Indeed, SBES or SMFC (sediment microbial fuel cell) was invented long ago [5, 6]. Electrochemically active bacteria, the key players in such a system, can oxidize organic matter in the sediment and the water and harvest electrons before transferring them to the anodic electrode [7]. With an external circuit connecting anode and the air cathode floating on the water surface, the system enables the oxidation of organic substances to be driven by a high redox potential difference, rather than by only anaerobic processes. Thus SBESs can offer in-situ reclamation of the water quality of aquaculture ponds with high efficiency and low cost, as the system can be reused and its operation is simple.

With the aim of taking such unique advantages of SBESs, Sajana and colleagues thoroughly investigated the efficiency of a laboratory scale SBES in treating the water of freshwater aquaculture ponds [1]. The system was shown to perform very well in removing Chemical oxygen demand (COD) and total nitrogen in the water of the experimented ponds [1]. Bioelectrochemical oxidation of organic substances and ammonium (nitrification) are believed to enhance such bioremediation, in addition to natural degradation. Their studies inspired us to investigate the possibility of installing an SBES in brackish aquaculture models and evaluate its bioremediation performance (our previous study [3]). Such a study is necessary because there are numerous aquaculture farms with brackish water all over the world and processes (including bioelectrochemical processes) under high salinity conditions might be absolutely different. Indeed, our previous study pointed out that unique bacteria, including Methylophilus rhizosphaerae, Desulfatitalea tepidiphila and Thiothrix eikelboomii, might play key roles in the SBES, rather than the popular electroactive ones such as Geobacter spp., Shewanella oneidensis or Pseudomonas spp. [3]. However, the system also performed relatively well, like the one reported by Sajana and colleagues, in terms of removing COD and nitrogen contents of the pond water and sediment. Those initial results suggest that the SBES technology has a potential application for in-situ reclaimation of water quality of brackish aquaculture systems.

Despite its promising treatment performance, a SBES, like any BES in general, can have varying responses when operated under different conditions [8, 9]. Operational parameters affecting the performance of a BES include uncontrollable factors such as $\mathrm{pH}$ of the electrolyte, ambient temperature, salt concentration or conductitvity, etc. and controllable factors such as external resistance, electrode spacing or the distance between electrodes, electrode material or configuration, etc. [4, 10-15]. Different parameters may affect the performance of a BES at different degrees. In general, some optimal conditions for SBES were proposed as follows: $\mathrm{pH} 7-8$ [16], high external resistance (e.g. $1000 \mathrm{ohm}$ ), temperature ranging from $20-35^{\circ} \mathrm{C}$ [15]. As for the freshwater SBES presented by Sajana and colleagues (2014), the following observations were reported: (i) various $\mathrm{pHs}$ could result in differences between COD removal and total nitrogen removal; (ii) increasing the distance between electrodes could increase the removals but not the power density; and decreasing the external resistance could increase the removals as well as the power generation [17]. Freshwater conditions and brackish water conditions are absolutely different, as they result in differences in salinity as well as conductivity 
levels of the envirionments, and ultimately in the bacterial "key players". Moreover, numerous aquaculture farms all over the world are operated with brackish water. Therefore, it is also necessary to understand how operational parameters affect the performance of the SBES working under brackish water conditions, which is the aim of this study. The factors we investigated include both controllable ones, such as external resistance and electrode spacing, and uncontrollable ones, such as $\mathrm{pH}$, temperature and salinity of the electrolyte, which actually vary and may very much affect brackish aquaculture ponds in practice. With an applied approach, we focused more on practical values (or "real life scenario" levels) of those parameters. Their effects were evaluated solely through COD and total nitrogen removal efficiencies, with reference to electricity generation, of the SBES. Particularly, such performance aspects of the SBES were always compared with those of the control, to ensure that the data obtained reflect the practically meaningful differences in the performances of the SBES versus natural degradation under different reallife operative conditions.

\section{Materials and Methods}

\section{Experimental Setup}

Two rectangular parallelepiped glass tanks (each having the dimensions of $30 \mathrm{~cm} \times 20 \mathrm{~cm} \times 25 \mathrm{~cm}$ ) that were previously constructed [3] (Fig. S1) were used as pond models in this study. One tank having a sediment bioelectrochemical system (SBES) installed was used as the test tank, while the other tank not having it served as the control. The SBES installed in the test tank consisted of a sediment anode and a cathode floating on the water surface (see detailed description in our previous study [3]). The sediment anode included a 2-cm-thick layer of graphite granules (3-5 $\mathrm{mm}$ in diameter) (Xilong Chemical Co., China) and an underlying graphite felt having the dimensions of $15 \mathrm{~cm} \times 7 \mathrm{~cm} \times$ $0.9 \mathrm{~cm}$ (Osaka Gas Chemicals Co., Japan). The cathode was a graphite felt of of the same size and type. Graphite rods glued to the graphite felts of the anode and the cathode for collecting current were connected with copper wires to an external resistor of $10 \Omega$. The sediment of the test tank was already enriched with an electricity-generating bacterial consortium and that of the control already inoculated with a microbial source from aquaculture ponds in the previous study [3].

In the default operation, pre-mixed artificial brackish water $(1.5 \%$ in salinity, prepared with Marinium Reef Sea salt (Mariscience International Co. Ltd., Thailand) as in the previous study [3] was used to fill each experimental tank to a level that is $10 \mathrm{~cm}$ distant from the tank bottom. Thus each tank had a final water volume of $6 \mathrm{~L}$ and its water body was just a $13^{3}$-fold miniature (with each dimension 13-fold miniaturized) of a $2.6 \mathrm{~m} \times$
$3.9 \mathrm{~m} \times 1.3 \mathrm{~m}$ water column of a typical aquaculture pond [3]. Each tank was fed with the shrimp feed GAMMA 6 (TOMBOY Co., Vietnam) at a rate of $0.051 \mathrm{~g} \mathrm{~d}^{-1}$ per tank, equivalent to a COD loading rate of $8 \mathrm{mg} \mathrm{l}^{-1} \mathrm{~d}^{-1}$, which mimicks the daily load of uneaten feed (assumed to be ca. 50\%) in an actual aquaculture pond with 30-day-old shrimp, as previously calculated [3]. The systems were operated at the default temperature of $30 \pm 2^{\circ} \mathrm{C}$ (typical average temperature of brackish aquaculture ponds in Vietnam).

\section{Experimental Procedures}

As mentioned above, when not experimented, the systems were operated under default conditions, which were: $\mathrm{pH}$ of the tank water (electrolyte) at 7 , temperature at $30^{\circ} \mathrm{C}$, salinity of the tank water at $1.5 \%$, electrode spacing at $10 \mathrm{~cm}$ and external resistance at $10 \Omega$. Depending on the specific experiments described below, one of those conditions could be varied while the others remained the same, unless otherwise stated.

Testing the effect of external resistance. With reference to a polarization curve and a power curve established prior to the experiment, the resistance levels to be focused on were determined to include $10,100,188,1,875$, and 4,690 $\Omega$, listed as in the testing sequence. The SBES was operated with each external resistance for 1 week and changes in its current density were monitored. Samples from both the test tank and the control were taken on the start date and the end date for COD, total nitrogen and $\mathrm{NH}_{4}{ }^{+} \mathrm{N}$ analyses to evaluate the bioremediation performance of the SBES (versus the control).

Testing the effect of distance between electrodes. According to aquaculture experts, in practice, depending on seasons, the water depth of a brackish aquaculture pond may vary up to $30 \%$ around the average value $(1.3 \mathrm{~m})$. Therefore, in this study, we tested the SBES with 3 levels of the distance between electrodes (actually equal to the water depth), including $10 \mathrm{~cm}$ (d, the default value), $7 \mathrm{~cm}(\mathrm{~d}-30 \% \mathrm{~d})$, and $13 \mathrm{~cm}(\mathrm{~d}+30 \% \mathrm{~d})$, listed as in the testing sequence. The water depth was adjusted by withdrawing tank water from each tank or by adding artificial brackish water (prepared as described above) to the tank to achieve the desired water level. The cathode position was accordingly adjusted so that the cathode floated on the water surface as described above. For each water depth, the test tank (containing the SBES) and the control were operated for 3 days. Samples were taken and analyzed as above. Other operational conditions were default and the same for both tanks.

Testing the effect of ambient temperature. Practically, temperature in aquaculture regions may drop down to $14^{\circ} \mathrm{C}$ and rarely exceeding $40^{\circ} \mathrm{C}$. Therefore, we evaluated the performance of the tanks when operated with several temperature levels within that range: $14^{\circ} \mathrm{C}, 25^{\circ} \mathrm{C}, 30^{\circ} \mathrm{C}, 35^{\circ} \mathrm{C}$, and $40^{\circ} \mathrm{C}$. These levels were tested in the following sequence: $30^{\circ} \mathrm{C}, 35^{\circ} \mathrm{C}, 40^{\circ} \mathrm{C}$, back to $30^{\circ} \mathrm{C}$, then down to $25^{\circ} \mathrm{C}, 14^{\circ} \mathrm{C}$, and finally back to $30^{\circ} \mathrm{C}$. To adjust the temperature, the tanks and all accompanying accesories were placed into a temperature-controlling chamber. At each 
temperature, the tanks were operated for 3 days. Samples were taken and analyzed as above. Other operational conditions were default and the same for both tanks.

Testing the effect of salinity. The salinity of brackish aquaculture ponds may vary due to seasonal changes. Thus in this study we tested the tanks with water having different salinities, including $0.5 \%, 1.0 \%, 1.5 \%, 2.0 \%$, and $2.5 \%$. These levels were tested in the following sequence: $1.5 \%, 2.0 \%, 2.5 \%$, back to $1.5 \%$, then down to $1.0 \%, 0.5 \%$, and finally back to $1.5 \%$. The salinity of the water was adjusted by adjusting the concentration of Marinium Reef Sea salt (Mariscience International Co. Ltd., Thailand) in the tank water with a salinity meter (model RHSN-10 ATC, Grand-index, China). Accordingly, the tanks were operated for 3 days with the water having its salinity adjusted to each salinity level to be tested. Samples were taken and analyzed as above. Other operational conditions were default and the same for both tanks.

Testing the effect of $\mathrm{pH}$ of the pond water. According to aquaculture experts, practical $\mathrm{pH}$ in actual brackish aquaculture ponds can decrease down to about 5.5 or increase up to 8.8 . Therefore, we tested our systems with three levels of $\mathrm{pH}$ of the tank water: 7, 8.8, and 5.5, listed as in the testing sequence. $\mathrm{pH}$ was adjusted by adding $\mathrm{HCl}$ or $\mathrm{NaOH}$ to the tank water. Accordingly, the test tank (containing the SBES) and the control were operated for 3 days with water having its $\mathrm{pH}$ adjusted to each $\mathrm{pH}$ level to be tested. Samples were taken and analyzed as above. During the experiment, the SBES was operated with a $100 \Omega$ external resistance. Other operational conditions were default and the same for both tanks.

\section{Sampling}

Sampling was carried out as described in the previous study [3]: Each sediment sample (ca. $5 \mathrm{~g}$ ) was the mixture of the mud collected at 5 points ( 4 at the corners and 1 at the center) of the sediment of each tank by spooning. The samples were stored at $-20^{\circ} \mathrm{C}$ for $\mathrm{COD}$, total nitrogen and $\mathrm{NH}_{4}{ }^{+} \mathrm{N}$ analyses. Water samples (ca. $20 \mathrm{ml}$ each, in triplicate) (for COD, total nitrogen and $\mathrm{NH}_{4}{ }^{+}-\mathrm{N}$ analyses) were also collected at the middle level of the water body of each tank (vertically ca. $5 \mathrm{~cm}$ from the bottom) at the same moments. As a large sample amount was required for each total nitrogen measurment, under each experimental condition, we could only take one sample for that measurment, in order not to seriously disturb the systems. Samples were taken at the beginning and at the end of each experiment.

\section{Measurement and Calculation}

The voltage between the anode and the cathode of the SBES installed in the test tank was monitored with a real-time digital multimeter (Keithley model 2700, Keithley Instruments Inc., USA). The measurements and calculations of electrical parameters (current $\mathrm{I}(\mathrm{A})$, voltage $\mathrm{U}(\mathrm{V})$, power $\mathrm{P}(\mathrm{W})$ and resistance $\mathrm{R}(\mathrm{W})$ ) follow Aelterman et al. (2006) [18] and Logan et al. (2006) [19]. Internal resistance was measured specifically by polarization slope method [20]. The potential of the anode or the cathode was measured against a $\mathrm{Ag} / \mathrm{AgCl}$ reference electrode (BASI, IN, USA) placed in the tank water at a distance of about $3 \mathrm{~cm}$ from the electrode. A polarization curve and a power curve to evaluate the electrochemical performance of the SBES, when operated under default conditions, were determined by applying the standard method [19]. Power density and current density were calculated with the total anode surface area of $1.08 \mathrm{~m}^{2}$, as estimated in the previous study (see our previous study [3] or Suppl.).

Chemical analyses were conducted as described in the previous study [3]: The COD of each sample was measured by the closed reflux colorimetric method [21] after the sample was pre-treated with $\mathrm{HgSO}_{4}$ [22]. Total nitrogen amount of each sample was measured by the Kjeldahl method and $\mathrm{NH}_{4}{ }^{+}$-nitrogen concentration was measured by the Nessler method [21]. To prevent the interference of chloride, $0.1 \mathrm{~N} \mathrm{Na}_{2} \mathrm{~S}_{2} \mathrm{O}_{3}$ solution was used (one drop for every $0.3 \mathrm{mg} \mathrm{l}^{-1} \mathrm{Cl}^{-}$) (USEPA method 8038).

Unless otherwise stated, all the values of the parameters reported in this study were the results of at least 3 repetitions.

\section{Data Processing and Analysis}

COD, total Kjeldahl nitrogen (TKN) or total ammonium nitrogen (TAN) removal was calculated as the percentage of the amount of the respective parameter removed at the end of each experiment (vs. the amount at the beginning). If the removal was $\leq 10 \%$, it is considered as not stastically meaningful, i.e. the removal was not significant. Data for the control were upon measurements done with the samples from the control (tank) at the same experimental moments. The calculation for the control was the same as for the test tank.

In this study, in order to have the most practical evaluation of the effects of the operational parameters on the performance of the SBES, we always compared the COD removal or the nitrogen removal of the SBES with those of the control, to know how better the SBES could actually improve those bioremediation aspects versus natural degradation. Therefore, the term "(COD, TKN or TAN) removal efficiency difference of the test tank (or the SBEScontaining tank, or the SBES) versus the control" presented in this study was the percentage of the respective parameter that was removed more by the test tank (containing the SBES) compared to the control.

Data were analyzed by using basic statistical methods with tools in Microsoft Excel: differences in data were evaluated by $t$ Test analysis; errors among replicates were expressed in the form of standard deviations.

\section{Results}

Polarization Curve and Power Curve of the SBES Integrated in a Brackish Aquaculture Pond Model

In order to comprehensively evaluate the electricity generation capacity of the SBES, its polarization curve and 


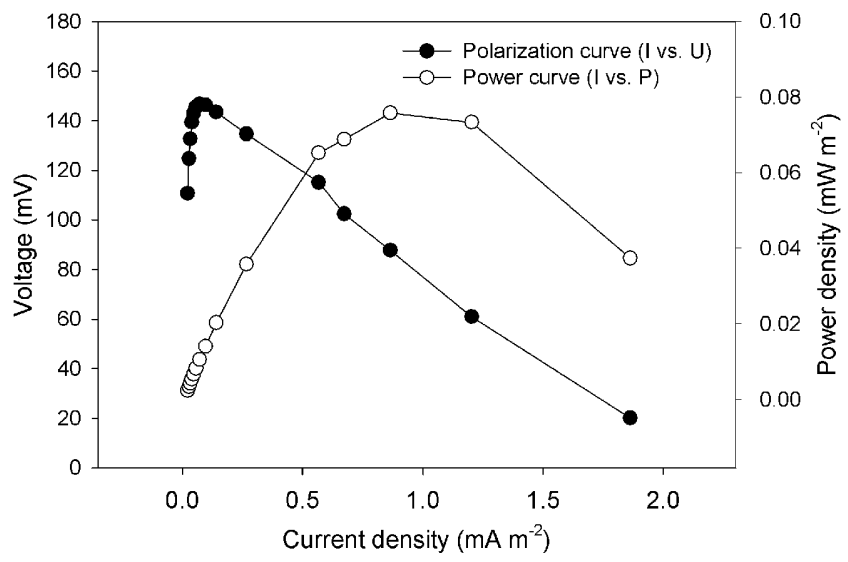

Fig. 1. Polarization curve and power curve of the SBES integrated in the brackish aquaculture pond model (the test tank).

The system was operated under default conditions $\left(\mathrm{pH} 7,30^{\circ} \mathrm{C}, 1.5 \%\right.$ salinity and $10 \mathrm{~cm}$ electrode spacing), except that the external resistance was varied. Three replications of the experiment showed similar results and thus only one representative was presented here.

power curve were determined as described above, when all operational conditions were default $\left(\mathrm{pH} 7,30^{\circ} \mathrm{C}, 1.5 \%\right.$ salinity and $10 \mathrm{~cm}$ electrode spacing). Its polarization curve (Fig. 1) showed that the maximum working voltage it could create was about $150 \mathrm{mV}$, at an external resistance of about $1,876 \Omega$. Its power curve (Fig. 1) showed a maximum attainable power density of about $0.08 \mathrm{~mW} \mathrm{~m}^{-2}$, at an external resitance of about $100 \Omega$. It can also be deduced from the curves that the maximum current density that the system could achieve is around $2 \mathrm{~mA} \mathrm{~m}^{-2}$.

\section{Effect of External Resistance}

The SBES was tested with increasing external resistance levels, including $100 \Omega$ and $1,876 \Omega$ that are the conditions at which the system could produce the maximum power and the maximum voltage, respectively. This is to investigate how the system performs, under these conditions, in terms of COD and nitrogen removals.

In terms of electricity generation, generally when the external resistance increased the current generated by the SBES decreased but it exceptionally reached the highest level at the external resistance of $100 \Omega$ (not at $10 \Omega$ ) (Fig. 2A). Specifically, at $100 \Omega$, the current generated by the SBES was at a level of around $1.7 \mathrm{~mA} \mathrm{~m}^{-2}$, definitely much higher than those at $188,1,875$, and $4,690 \Omega$, which were around $0.83 \mathrm{~mA} \mathrm{~m}^{-2}, 0.28 \mathrm{~mA} \mathrm{~m}^{-2}$ and $0.11 \mathrm{~mA} \mathrm{~m}^{-2}$, respectively. At $10 \Omega$, the current density was around
$1.65 \mathrm{~mA} \mathrm{~m}^{-2}$, slightly lower than that at $100 \Omega$, though this difference is not significant $(p>0.05)$.

The COD removal results (Fig. 3A) showed that, like in the previous study [3], generally the test tank could remove COD of the pond water around $20 \%$ more efficiently than the control, i.e. the SBES could enhance the water COD removal by about that rate if compared with natural degradation. Changing the external resistance did not seem to affect the efficiency difference regarding water COD removal between the two tanks. However, the observations were not the same for the removal of sediment COD. In consistent with the previous study [3], at the external resistance of $10 \Omega$, the sediment COD removals by the test tank and by the control were not significantly different (Fig. 3D). However, when increasing the resistance, it was surprising that the test tank removed sediment COD much more efficiently than the control. The maximum removal efficiency difference of $28 \pm 6 \%$ was achieved at the external resistance level of $100 \Omega$. The removal efficiency difference seemed to decrease when the external resistance increased above $100 \Omega$, and it was unexpectedly negligible at $188 \Omega$ (Fig. 3D). Thus, the changes in the COD removing performance of the SBES in response to the changes in external resistance seemed to be almost correlated to the changes of its electricity generation, which showed the maximum level at $100 \Omega$.

Regarding total nitrogen removal, it is striking that the test tank removed TKN of the water $25-30 \%$ more efficiently than the control when operated with the external resistances of $100 \Omega$ and $188 \Omega$, while it did not do better with other resistance levels (Fig. 3B). On the other hand, the test tank removed TKN of the sediment $(20-25 \%)$ more efficiently when operated with the external resistances of $188 \Omega$ and $1,875 \Omega$, while it did not do better with other resistance levels (Fig. 3E). With respect to total ammonium nitrogen removal, when operated with the resistances other than $10 \Omega$, the test tank showed significantly improved $\mathrm{NH}_{4}{ }^{+}-\mathrm{N}$ removals for both water and sediment, compared to the control (Figs. 3C and 3D). Notably, at the external resistance level of $188 \Omega$, the removal efficiency difference could maximally reach $43.2 \pm 2.4 \%$ for water TAN and $39.7 \pm 4.6 \%$ for sediment TAN (Figs. 3C and 3D). In summary, it can be seen clearly from the results that operating the SBES with the external resistance of $188 \Omega$ could significantly increase its nitrogen removal efficiency difference versus natural degradation. Thus, unlike the changes in the COD removing performance, the changes in the nitrogen removing performance of the SBES in response to the changes in external resistance was not fully 

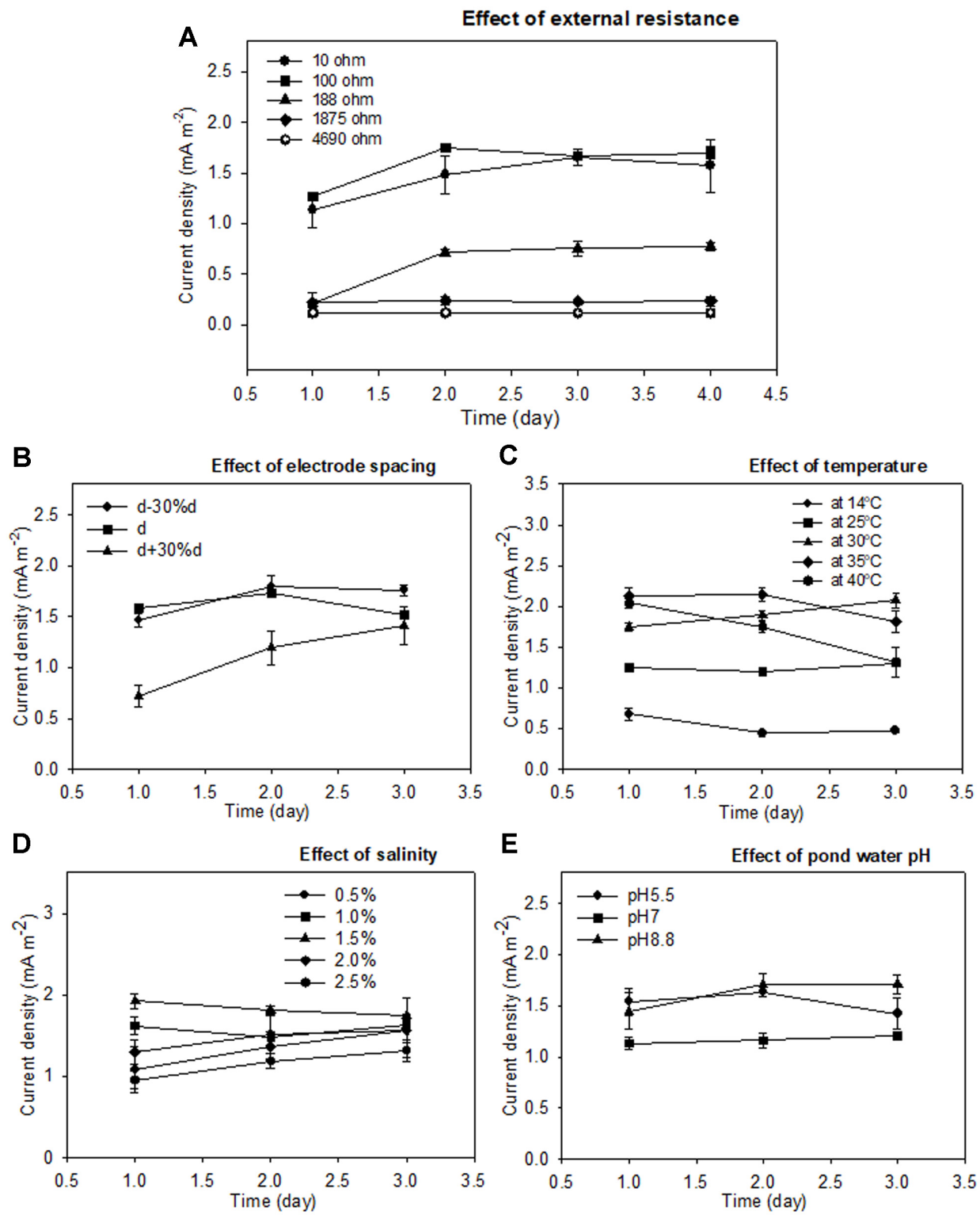

Fig. 2. Effect of external resistance (A), electrode spacing (B), ambient temperature (C), salinity of the pond water (D), and pH of the pond water (E) on the generation of electrical current by the SBES integrated in the brackish aquaculture pond model (the test tank).

The system was operated under default conditions, except that the tested parameter was varied (as described in section 2.2). Shown here are average values and standard deviations of three replications in each experiment.

correlated to the changes in its electricity generation.

\section{Effect of the Distance between Electrodes}

As mentioned, in practice the water depth of a brackish aquaculture pond may vary up to $30 \%$ around the average value. Therefore, the test tank and the control were tested with 3 levels of water depth (actually equal to 3 levels of the distance between the electrodes of the SBES), including
$10 \mathrm{~cm}$ (d, the default value), $7 \mathrm{~cm}(\mathrm{~d}-30 \% \mathrm{~d})$, and $13 \mathrm{~cm}$ $(\mathrm{d}+30 \% \mathrm{~d})$ and their performance evaluated.

The generation of electricity by the SBES did not change when the electrode spacing was reduced by 30\% (Fig. 2B). However, when the electrode spacing increased by $30 \%$, the current density decreased to less than $1.4 \mathrm{~mA} \mathrm{~m}^{-2}$, significantly lower than that with the default electrode distance, which was around $1.78 \mathrm{~mA} \mathrm{~m}^{-2}$ (Fig. 2B). This 

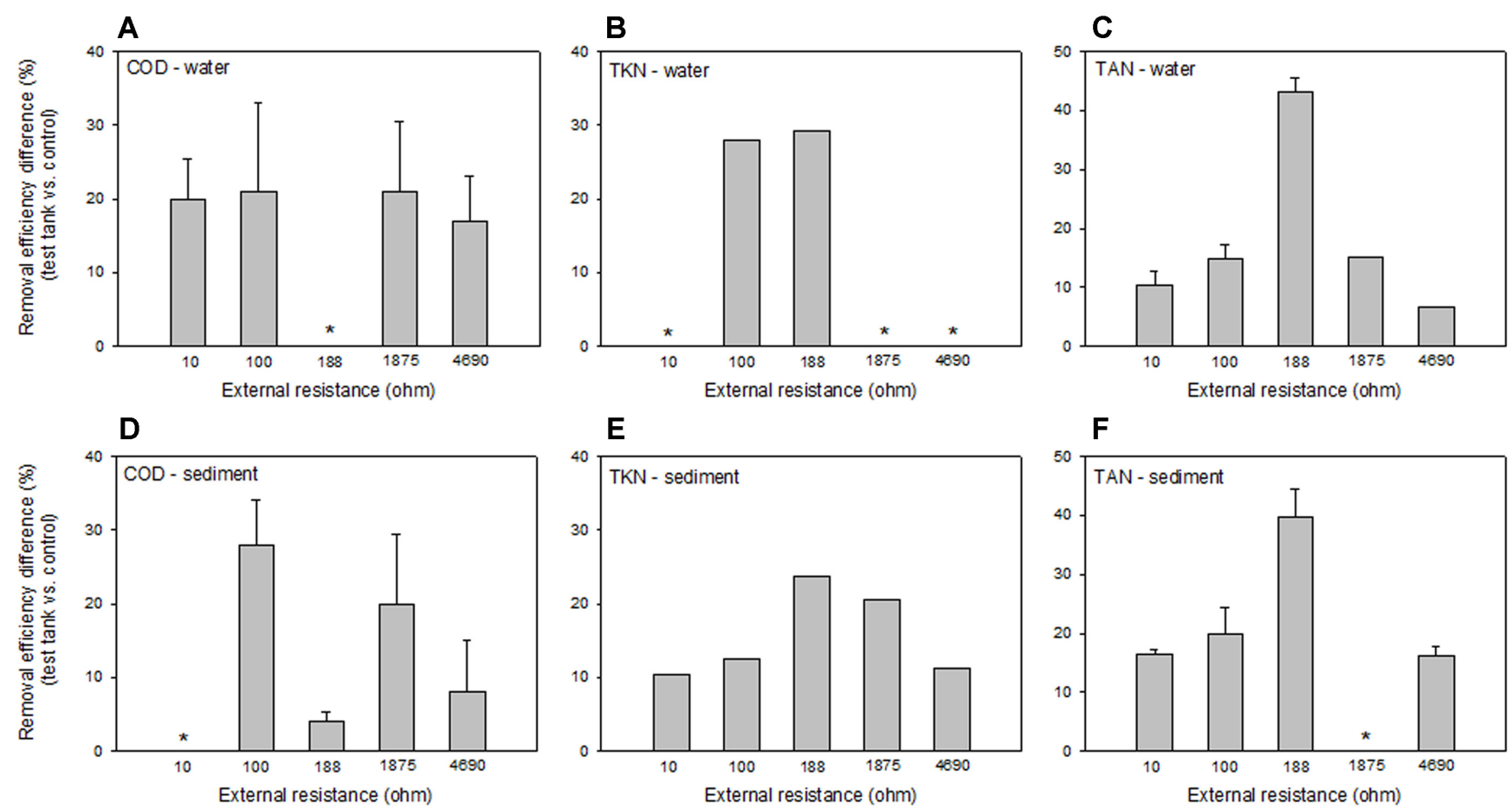

Fig. 3. Effect of changing external resistance on the removal efficiency difference of the test tank (containing the SBES) (vs. the control) in terms of: COD of the pond water (A), TKN of the water (B), TAN of the water (C), COD of the sediment (D), TKN of the sediment $(\mathbf{E})$, and TAN of the sediment $(\mathbf{F})$.

The systems were operated under default conditions $\left(\mathrm{pH} 7,30^{\circ} \mathrm{C}, 1.5 \%\right.$ salinity and $10 \mathrm{~cm}$ electrode spacing), except that the external resistance was varied. Shown here are average values and standard deviations of three replications in each experiment, except for those of TKN measurements, which could not be repeated (as explained in section 2.3). *Indicates a case where both the removal efficiencies of the test tank and the control were $<10 \%$ and thus the removal efficiency difference was statistically considered insignificant.

change in the electricity generation by the SBES in response to electrode spacing change is quite opposite to the changes of COD and nitrogen removals, as explained below.

Operated with the default electrode distance, the test tank could remove COD of the water around 20\% more efficiently than the control (Fig. 4A). Reducing the distance by $30 \%$ could slightly reduce the removal efficiency difference, while increasing it by $30 \%$ could significantly increase the removal efficiency difference up to ca. $30 \%$ (Fig. 4A) $(p<0.05)$. In terms of removing COD of the sediment, it is striking that the SBES, when operated with the default electrode distance, could not perform better than the control (natural degradation) but it did 15\% better when operated with $\mathrm{d}-30 \% \mathrm{~d}$ and $18 \%$ more efficiently with d+30\%d (Fig. 4D).

Regarding the removal of total nitrogen in the water, while with the default electrode spacing the test tank only performed about $10 \%$ more efficiently than the control, it did $15 \%$ more efficiently when the electrode distance increased by $30 \%$, and slightly better with $\mathrm{d}-30 \% \mathrm{~d}$ (Fig. 4B). With respect to nitrogen removal of the sediment, increasing the electrode spacing did not seem to improve the performance of the SBES versus the control (Fig. 4E). However, the reduced electrode distance seemed to boost up (by $\sim 24 \%$ ) the removal of total nitrogen in the sediment by the SBES versus the control (natural degradation) (Fig. 4E).

Unlike the observations with total nitrogen in the sediment, the removal of total ammonium nitrogen in the sediment by the SBES (with the default electrode distance) was about $20 \%$ more efficient than that by the control. This figure decreased (to ca. 15\%) when the electrode distance decreased by $30 \%$ and significantly increased to ca. $30 \%$ when the electrode distance increased by $30 \%$ (Fig. 4F). For the ammonium nitrogen of the water, the results was less encouraging, showing little difference in the performance between the SBES and the control, although the SBES appeared to perform slightly more efficiently (by about $5 \%$ ) 
A

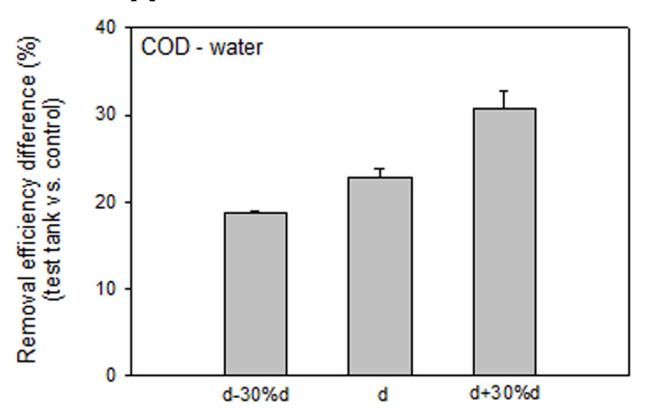

D

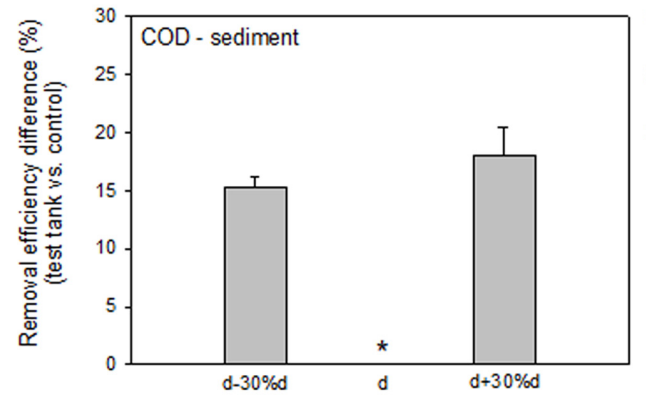

B

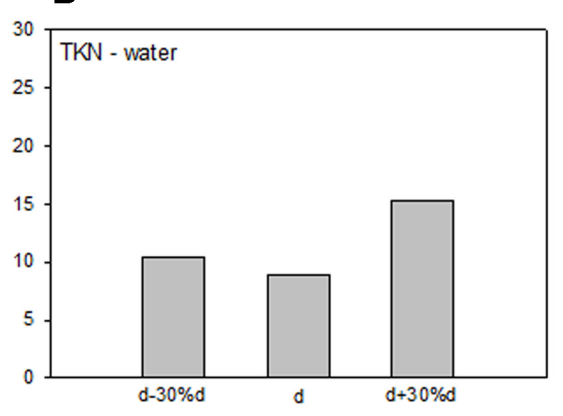

E

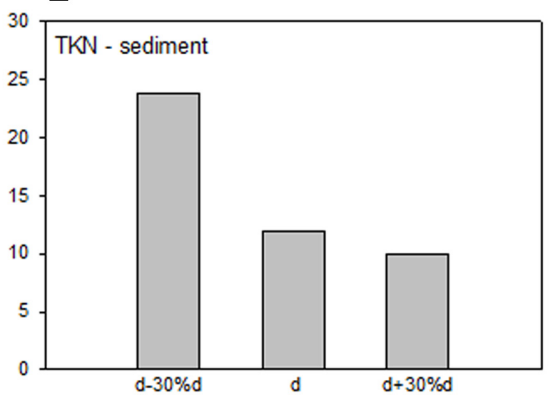

C

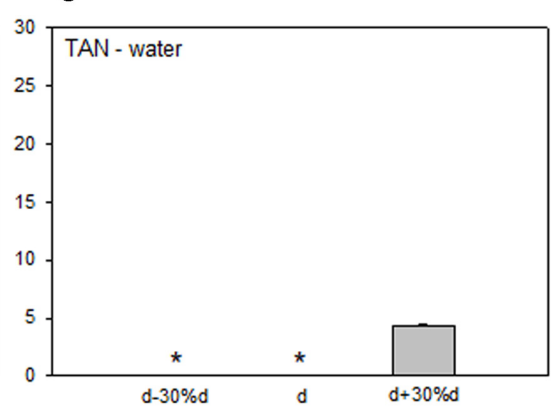

F

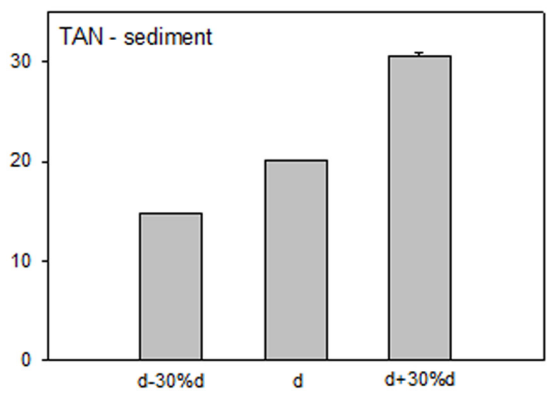

Fig. 4. Effect of changing the electrode spacing on the removal efficiency difference of the test tank (containing the SBES) (vs. the control) in terms of: COD of the pond water (A), TKN of the water (B), TAN of the water (C), COD of the sediment (D), TKN of the sediment (E), and TAN of the sediment (F).

The systems were operated under default conditions $\left(\mathrm{pH} 7,30^{\circ} \mathrm{C}, 1.5 \%\right.$ salinity and $10 \Omega$ external resistance), except that the electrode spacing was varied. $d$ : the default distance between the two electrodes $=10 \mathrm{~cm} ; d+30 \%$ : the distance with $30 \%$ increase compared to the default; $d-30 \%$ : the distance with $30 \%$ decrease compared to the default. Shown here are average values and standard deviations of three replications in each experiment, except for those of TKN measurements, which could not be repeated (as explained in section 2.3). *Indicates a case where both the removal efficiencies of the test tank and the control were $<10 \%$ and thus the removal efficiency difference was statistically considered insignificant.

with $\mathrm{d}+30 \% \mathrm{~d}$.

Altogether, although some data remain to require further explanation, the results indicate a trend that increasing the electrode spacing (by 30\%) can improve the COD and nitrogen removal efficiency differences of the SBES versus natural degradation while reducing it can not.

\section{Effect of Temperature}

The experimental tanks were tested with a temperature variation close to that in practice (real life): $14^{\circ} \mathrm{C}, 25^{\circ} \mathrm{C}$, $30^{\circ} \mathrm{C}, 35^{\circ} \mathrm{C}$, and $40^{\circ} \mathrm{C}$. The density of electrical current generated by the SBES reached the highest value of $2.15 \pm$ $0.08 \mathrm{~mA} \mathrm{~m}^{-2}$ at $35^{\circ} \mathrm{C}$, while it was ca. $1.94 \mathrm{~mA} \mathrm{~m}^{-2}$ at $30^{\circ} \mathrm{C}$ (Fig. 2C). It showed significant signals of declination at $40^{\circ} \mathrm{C}$ and clearly decreased down to ca. $1.28 \mathrm{~mA} \mathrm{~m}^{-2}$ at $25^{\circ} \mathrm{C}$ and to a very low level of ca. $0.44 \mathrm{~mA} \mathrm{~m}^{-2}$ at $14^{\circ} \mathrm{C}$ (Fig. 2C).

The changes in the electricity generation by the SBES in response to temperature changes suggest that $C O D$ and nitrogen might be removed more efficiently at high temperatures. However, it is interesting that the temperatures higher than $30^{\circ} \mathrm{C}$ (the default value) did not result in more efficient COD and nitrogen removals of the test tank versus the control (Fig. 5). The only exception is the $18 \%$ higher water TKN removal efficiency of the SBES (vs. the control) achieved at $35^{\circ} \mathrm{C}$ (Fig. 5B). On the other hand, at $25^{\circ} \mathrm{C}$, significant improvements of the SBES performance (vs. the control) in removing COD and total nitrogen of sediment could be observed, with the removal efficiency differences reaching nearly $10 \%$ for COD and $24 \%$ for TKN (Figs. 5D and 5E). $25^{\circ} \mathrm{C}$ was also the only temperature (other than the default $30^{\circ} \mathrm{C}$ ) at which the SBES did perform more efficiently than the control in removing water COD (Fig. 5A). At the lower temperature limit $\left(14^{\circ} \mathrm{C}\right)$, the SBES even performed worse than the control in removing COD and total nitrogen, though the SBES-versus-control removal efficiency differences still 


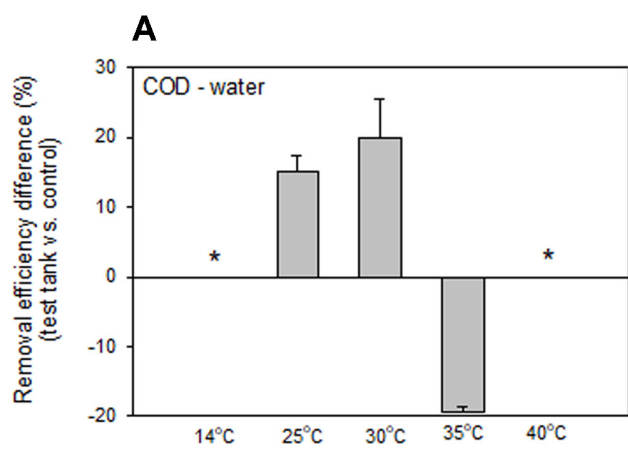

D
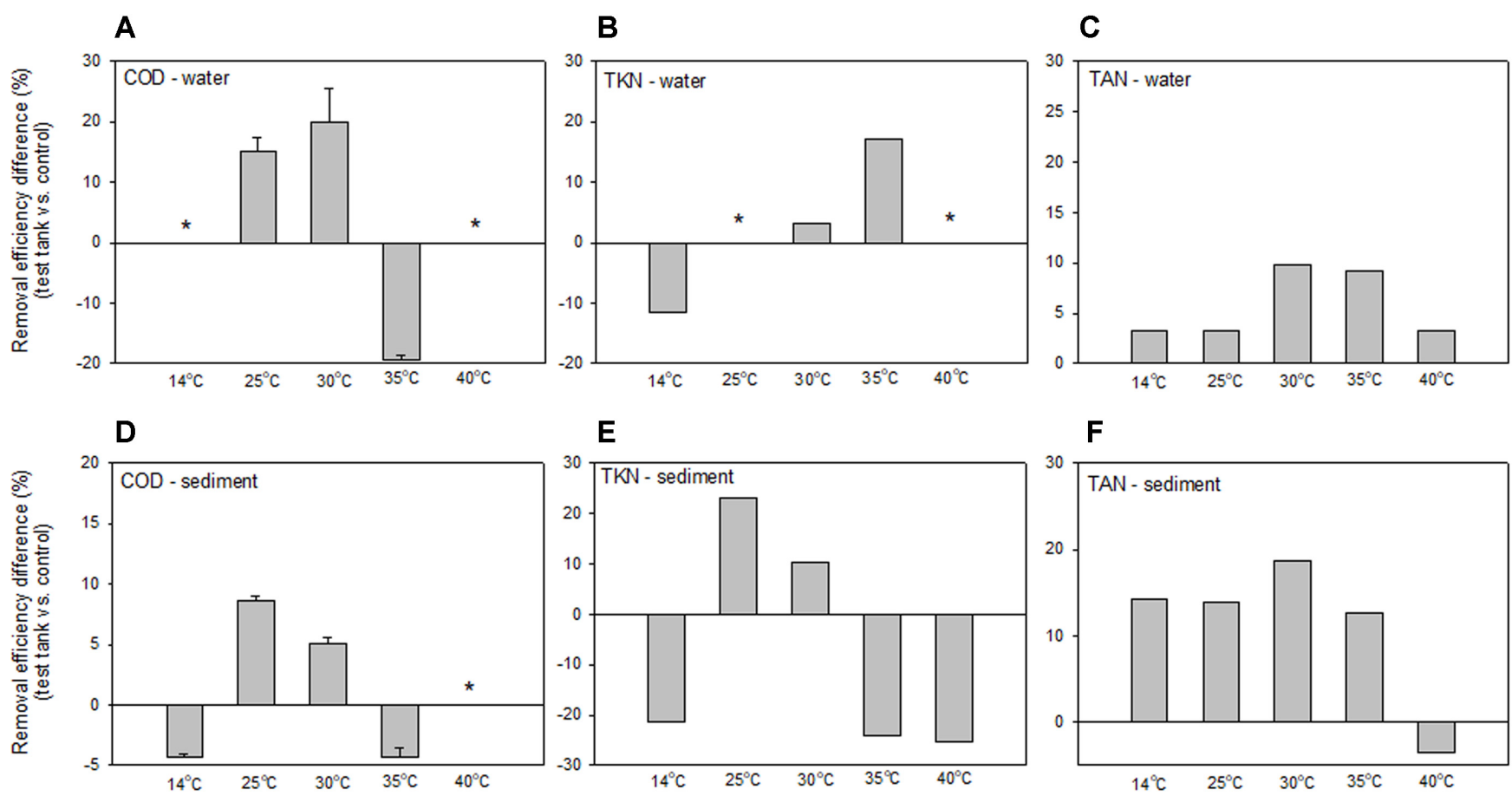

\section{E}

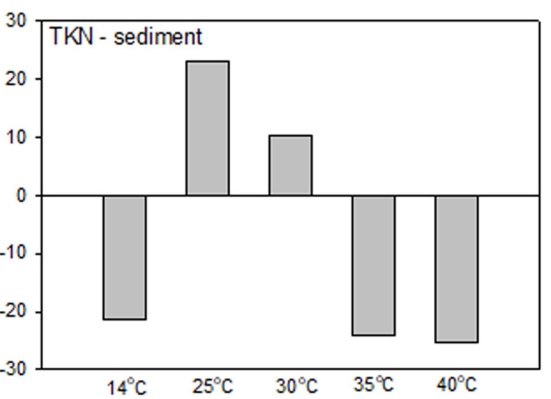

$\mathbf{F}$

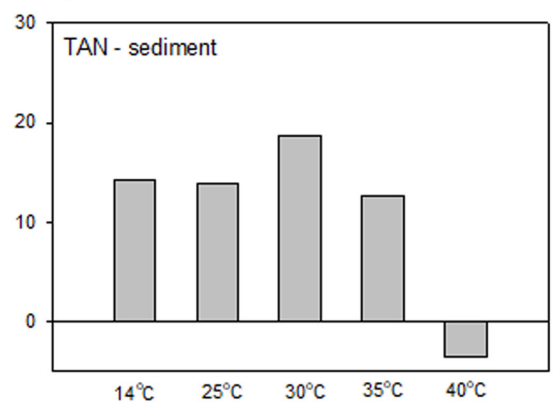

Fig. 5. Effect of changing the ambient temperature on the removal efficiency difference of the test tank (containing the SBES) (vs. the control) in terms of: COD of the pond water (A), TKN of the water (B), TAN of the water (C), COD of the sediment (D), TKN of the sediment $(\mathbf{E})$, and TAN of the sediment $(\mathbf{F})$.

The systems were operated under default conditions ( $\mathrm{pH}$ 7, 1.5\% salinity, $10 \mathrm{~cm}$ electrode spacing and $10 \Omega$ external resistance), except that the ambient temperature was varied with a temperature-controlling chamber. Shown here are average values and standard deviations of three replications in each experiment, except for those of TKN measurements, which could not be repeated (as explained in section 2.3). *Indicates a case where both the removal efficiencies of the test tank and the control were $<10 \%$ and thus the removal efficiency difference was statistically considered insignificant.

remained at ca. $3 \%$ for water TAN and ca. $14 \%$ for sediment TAN - still lower than those at $30^{\circ} \mathrm{C}$ (Figs. 5C and 5F).

Altogether, our results show that the SBES-containing tank performed only slightly better than the control (natural degradation) in removing COD and nitrogen when the temperature was within the optimal range of 25$30^{\circ} \mathrm{C}$. Outside that range, the former seemed not more efficient or even less efficient than the latter.

\section{Effect of the Salinity of the Pond Water}

The experimental tanks were tested with varied levels of the salinity of the pond water (as can be assumingly resulted from seasonal changes), including: 0.5\%, $1.0 \%$, $1.5 \%, 2.0 \%$ and $2.5 \%$. The results showed that the electrical current generated by the SBES decreased when the salinity changed to the levels other than $1.5 \%$ (the default mode level) (Fig. 2D). Specifically, the curent was reduced by about $20 \%$ when the salinity was changed by $0.5 \%$ (to $1.0 \%$ or $2.0 \%$ ) from the default mode level, and was even reduced further when the salinity was changed more (to $0.5 \%$ or $2.5 \%$ ) (Fig. 2D). $2.5 \%$ was the salinity that caused the most reduction (of about $40 \%$ ).

In contrast to its effect on the electricity generation of the SBES, regarding the removal of COD in the water, the effect of salinity on the removal efficiency difference of the SBES (vs. the control) was not significant (Fig. 6A). The removal efficiency difference ranged from about $20-30 \%$, with little differences between the cases of different salinity levels, although the lowest difference seemed to be at $2.5 \%$ salinity. However, regarding the removal of COD in the sediment, it is unpredictable that the salinity levels of $1.0 \%$ and $2.0 \%$ led to significantly improved removal efficiency differences of the SBES (vs. the control) $(p<0.05)$ : $20 \pm 1 \%$ and $22.7 \pm 6.7 \%$, respectively, versus only about $5.7 \%$ at $1.5 \%$ salinity (Fig. 6D).

With respect to nitrogen removal, it is noticeable that the salinity levels other than $1.5 \%$ (the default) generally did not improve the performance of the SBES versus the 
A

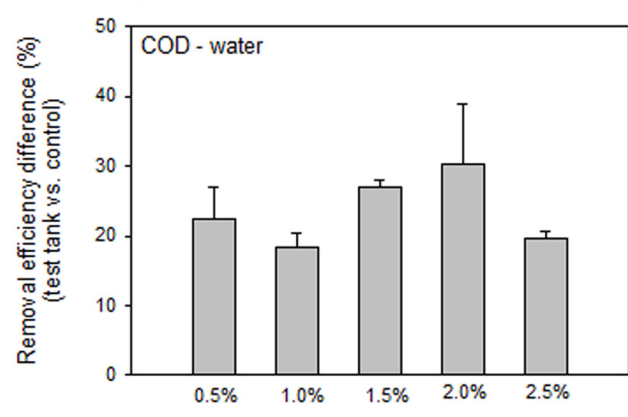

D

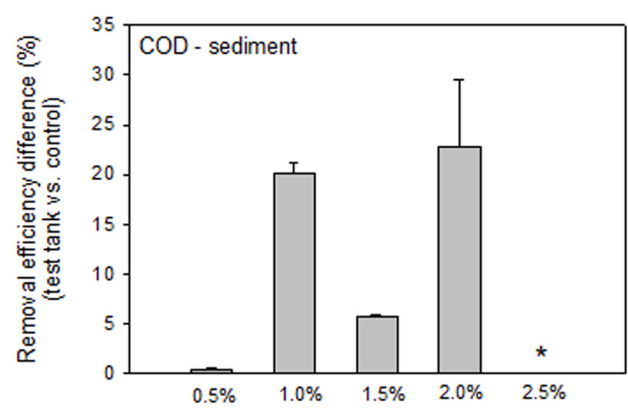

B

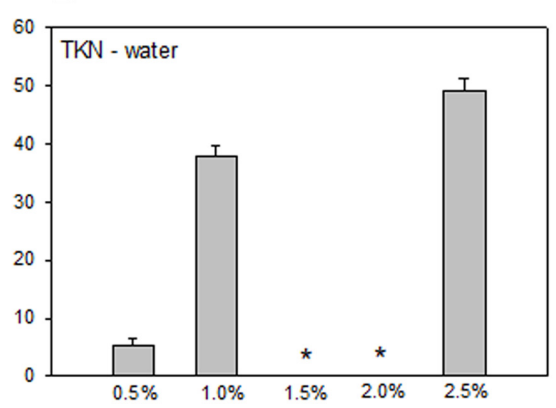

E

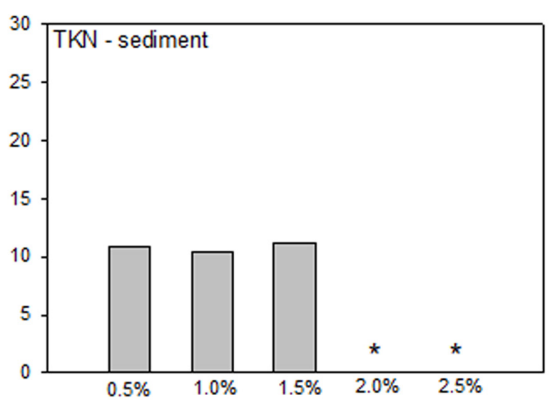

C

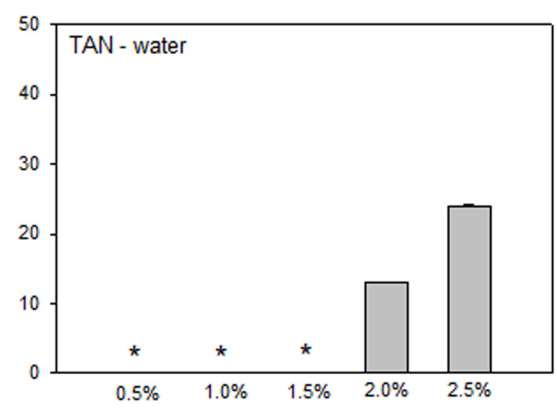

F

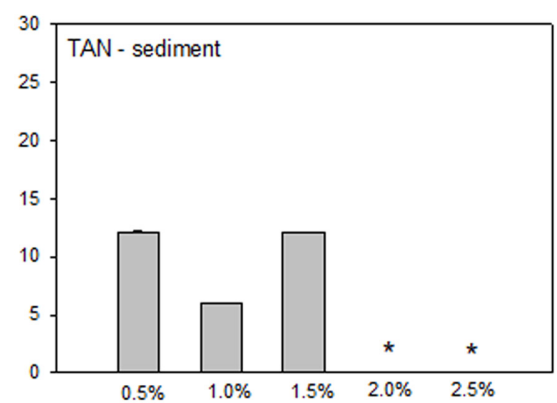

Fig. 6. Effect of changing the salinity of the water on the removal efficiency difference of the test tank (containing the SBES) (vs. the control) in terms of: COD of the pond water (A), TKN of the water (B), TAN of the water (C), COD of the sediment (D), TKN of the sediment $(\mathbf{E})$, and TAN of the sediment $(\mathbf{F})$.

The systems were operated under default conditions $\left(\mathrm{pH} 7,30^{\circ} \mathrm{C}, 10 \mathrm{~cm}\right.$ electrode spacing and $10 \Omega$ external resistance), except that the salinity of the water was varied from the default level of $1.5 \%$ to $0.5 \%, 1.0 \%, 2.0 \%$, or $2.5 \%$. Shown here are average values and standard deviations of three replications in each experiment, except for those of TKN measurements, which could not be repeated (as explained in section 2.3). ${ }^{*}$ Indicates a case where both the removal efficiencies of the test tank and the control were $<10 \%$ and thus the removal efficiency difference was statistically considered insignificant.

control, except the level of $2.5 \%$ (Figs. 6B, 6C, 6E, and 6F). With the salinity of $2.5 \%$, the removal of nitrogen in the water of the test tank (containing the SBES) was particularly more efficient than the control, with the removal efficiency differences reaching ca. $24 \%$ for ammonium-nitrogen and even ca. 50\% for TKN (Figs. 6B and $6 \mathrm{C}$ ). Under this condition, however, the removal efficiency differences for ammonium and TKN in the sediment were not significant (Figs. 6E and 6F). Another noticeable result is the improved performance of the SBES (vs. the control) in removing TKN at the salinity level of $1.0 \%$, at which however no improvement could be observed in ammonium-nitrogen removal. Specifically, at $1.0 \%$ salinity, the SBES could remove TKN of the water $\sim 40 \%$ more efficiently than the control (Figs. $6 \mathrm{~B}$ and $6 \mathrm{E}$ ), while it did not do better in removing ammonium-nitrogen (Figs. 6C and 6F).

\section{Effect of $\mathrm{pH}$ of the Pond Water}

Based on the results above, in order to evaluate more correctly the performance of the tanks, we selected the external resistance of $100 \Omega$ for the test of the effect of $\mathrm{pH}$, because such external resistance enhanced both the COD and nitrogen removal efficiency differences of the SBES versus the control. $\mathrm{pH}$ of the tank water was changed to 5.5 or 8.8 , which are the possible extreme values of $\mathrm{pH}$ in real operative conditions. In response to these $\mathrm{pH}$ changes, the changes of electricity generation by the SBES were somewhat unexpected. Specifically, the currents increased by about 1.5 fold at both the reduced $\mathrm{pH}$ of 5.5 and the increased $\mathrm{pH}$ of 8.8 (Fig. 2E).

When being tested with those practically extreme $\mathrm{pHs}$, the COD and TKN removal efficiency differences between the SBES and the control were reduced (Fig. 7). Specifically, the removal efficiency difference for water COD decreased to ca. $15 \%$ at $\mathrm{pH} 5.5$, while at $\mathrm{pH} 7$ it was around $20 \%$ (Fig. 7A). Also at $\mathrm{pH}$ 5.5, in terms of removing sediment COD, water TKN and sediment TKN, the SBES appeared to perform less efficiently than the control (Figs. 7B, 7D, and 7E). At $\mathrm{pH} 8.8$, the SBES performed even much less 
A

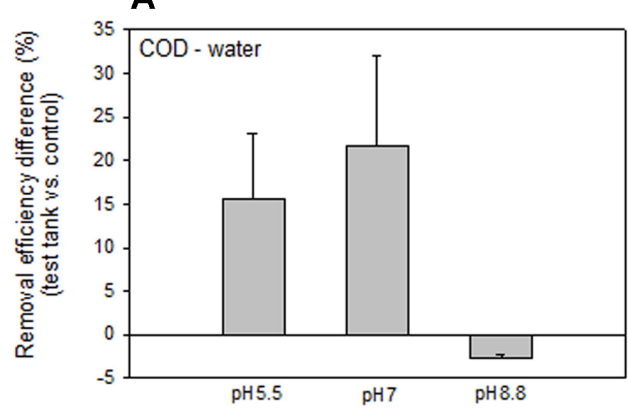

D

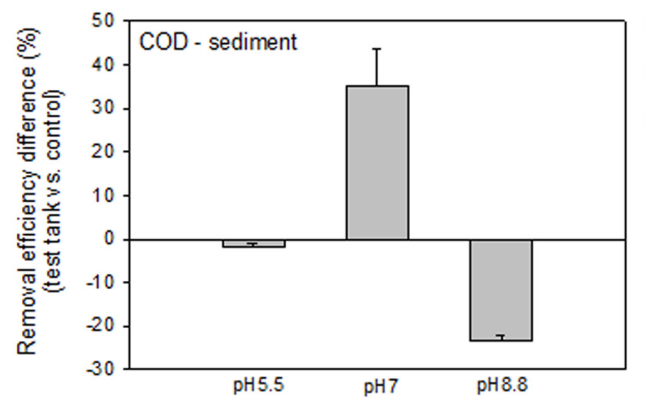

B

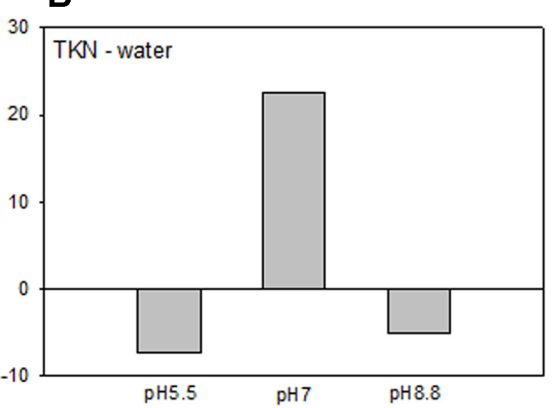

E

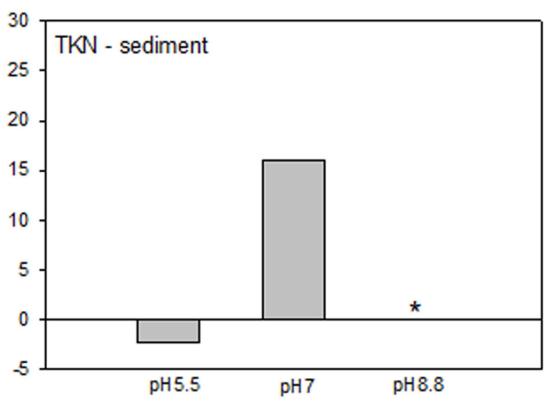

C

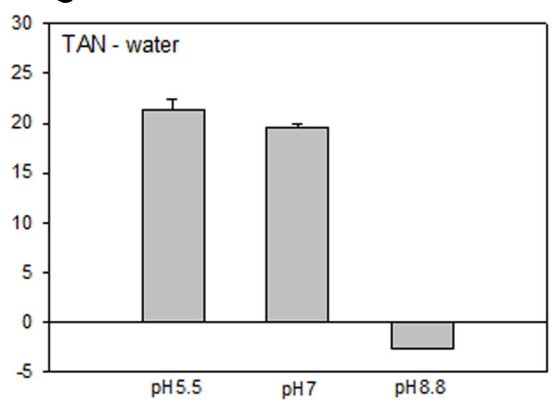

$\mathbf{F}$

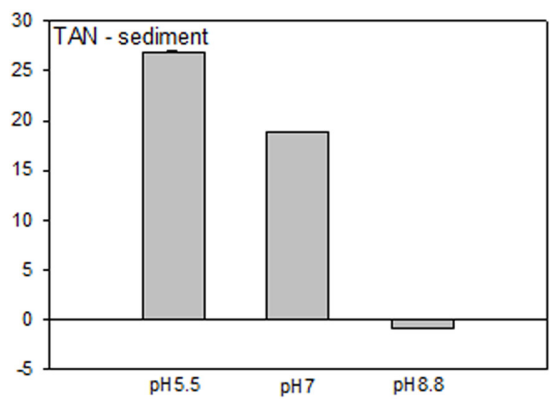

Fig. 7. Effect of changing the $\mathrm{pH}$ of the water on the removal efficiency difference of the test tank (containing the SBES) (vs. the control) in terms of: COD of the pond water (A), TKN of the water (B), TAN of the water (C), COD of the sediment (D), TKN of the sediment (E), and TAN of the sediment (F).

The systems were operated under default conditions $\left(30^{\circ} \mathrm{C}, 1.5 \%\right.$ salinity, $10 \mathrm{~cm}$ electrode spacing and $100 \Omega$ external resistance), except that $\mathrm{pH}$ of the water was varied from the default level of 7.0 to real-life extreme levels of 5.5 or 8.8. Shown here are average values and standard deviations of three replications in each experiment, except for those of TKN measurements, which could not be repeated (as explained in section 2.3). *Indicates a case where both the removal efficiencies of the test tank and the control were $<10 \%$ and thus the removal efficiency difference was statistically considered insignificant.

efficiently in terms of removing COD and TKN of both the water and the sediment (Figs. 7A, 7B, 7D, and 7E).

Regarding ammonium removal, the situation with pH 8.8 was more or less similar, meaning a poorer performance by the SBES (Figs. 7C and 7F). However, at $\mathrm{pH} 5.5$, the percentage of water TAN that the SBES could remove more (vs. the control) was $21.4 \pm 0.9 \%$, somewhat comparable to that at $\mathrm{pH} 7(19.6 \pm 0.3 \%)$ (Fig. 7C). The striking result was with sediment TAN removal at $\mathrm{pH} 5.5$, at which the SBES performed even ca. $27 \%$ more efficiently than the control, while it only did ca. $18 \%$ more efficiently at pH 7 (Fig. 7F).

A comprehensive remark from all the results above is that the SBES did not perform more efficiently than the control (or natural degradation) at the $\mathrm{pHs}$ other than 7, although a reduced $\mathrm{pH}$ of down to 5.5 could somehow further improve the removal of ammonium by the SBES versus the control.

\section{Discussion}

\section{Effect of Operational Conditions}

Operational parameters greatly influence the performance of BESs in general and SBESs in particular [9, 10, 15]. In this study, they also affected different performance aspects of the SBES installed in a brackish pond model at different degrees. Although based on previous studies it is supposed that the effects could be predicted, our experimental results showed that for a brackish system they were indeed generally unexpected and require careful explanation. Specifically, the effects of external resistance and electrode spacing were relatively similar to those reported previously for other systems but still with some exceptions, while the effects of temperature, salinity and $\mathrm{pH}$ of the pond water were significantly different and demonstrated distinct responses of the SBES when operated under brackish conditions. The details are discussed below. 
The external resistance affects the performance of a SBES by controlling the flow of electrons from anode to cathode [23]. At lower resistances, normally a BES generates higher currents due to the higher electron transfer to the cathode supporting a faster cathode reaction and a higher exoelectrogenic activity [10, 15, 23]. In this study, the tendency of the electricity generation change in response to the variation of the external resistance is relatively similar, except that the electrical current at $100 \Omega$ was even approximately equivalent to that at $10 \Omega$. This probably correlates to the tendency of changes in the COD removal efficiency difference of the SBES-containing tank versus natural degradation, also showing a maximum value at $100 \Omega$. Indeed, $100 \Omega$ was the external resistance at which the SBES could attain the maximum power. This also means that the energy conversion rate when the SBES was operated with $100 \Omega$ might be the highest, leading to the most efficient COD removal. Other studies also suggested better COD removals in correlation with higher electricity generations when the external resistance was reduced [10, 15, 23]. Sajana et al. [23] found that the external resistance of $0-52 \Omega$ was optimal for achieving optimal COD removal. In our study, the finding that the optimal resistance $(100 \Omega)$ for COD removal was the level at which the SBES produced the maximum power was noticeable and indeed reasonable, as discussed above. It should also be noted that at that resistance level, sediment COD was removed by the SBES even more efficiently than water COD, while at $10 \Omega$ it was not significantly removed. Actually, at $100 \Omega$ the anode potential was significantly shifted to around - $250 \mathrm{mV}$ (vs. Ag/ AgCl) (Fig. S2), a level that probably triggered a more vigorous break-down of the nearby sediment COD contents, compared to the masstransfer-limited water COD degradation [6], while that at $10 \Omega$ (around - $210 \mathrm{mV}$ vs. $\mathrm{Ag} / \mathrm{AgCl}$ ) might not be optimal to stimulate a clear sediment COD degradation. Indeed, it was reported that small changes of external resistance levels within the range of $<3,000 \Omega$ could result in great changes of the anode potential in a BES [24]. The anode redox potential shift could be also an explanation for the nitrogen removal results, which showed that $100 \Omega$ was not the best for nitrogen removal but higher external resistances, $188 \Omega$ in particular. The latter appeared to better boost the nitrogen removal efficiency difference of the SBES versus the control (natural degradation), probably due to lowered anode potentials [24]. In fact, it was lowered by around $30 \mathrm{mV}$ after the external resistance changed from $100 \Omega$ to $188 \Omega$ (Fig. S2). There has been clear evidence that lowering the redox potential could significantly enhance nitrification/denitrification [25] and even the anammox process [26], which are generally considered as the basic mechanisms for nitrogen removal. One may notice that the nitrogen removal by the system was not remarkably better with the higher external resistances of $1,875 \Omega$ and $4,690 \Omega$, although the resulted anode potentials were equal to or even lower than that with $188 \Omega$ (Fig. S2). However, in these cases, the system on the other hand underwent great shifts of the cathode potential (Fig. S2), which might hold back nitrogen removal although the reason for this is unclear. Thus, the tendency of changes in the nitrogen removal efficiency difference (between the SBES and the control) is not consistent with those of changes in the electricity generation and the COD removal efficiency difference. This is different from what was observed by Sajana et al. [23] with the freshwater SBES, showing the consistency between the changes in COD removal and those in nitrogen removal. Probably, in a brackish environment, where the density of ions is much higher, nitrogen removal, including ammonia removal, is even more affected by the redox potential.

Regarding the effect of electrode distance (or spacing), it is interesting to note that in this study, the (30\%) increased electrode spacing could significantly improve the COD and nitrogen removal performances of the SBES (vs. the control) while it resulted in poorer electricity generation. These tendencies were actually similar to what was observed with the freshwater systems [15, 23]. Liu et al. [14] reported a $67 \%$ increased electricity generation when the electrode spacing of their MFC was reduced by $50 \%$. Hong et al. [15] clearly showed that reducing the electrode spacing of a sediment MFC could result in proportionally increased electricity generation. The reason is believed to be the change in the internal resistance $[14,15]$. Indeed, in this study, the internal resistance of the system significantly increased (by about $20 \%, p<0.05$ ) when the default electrode spacing increased by $30 \%$, although it only decreased a little when the electrode spacing was reduced by $30 \%$ (Fig. S3). It is also a question how close the electrodes should be from each other, not only to minimize the internal resistance but also to avoid short circuit and oxygen diffusion $[14,15]$. This question becomes even more complicated because increasing the electrode spacing, on the other hand, could lead to increased COD and nitrogen removals, as also observed in the freshwater SBES reported by Sajana et al. [23]. Larger reactor volumes resulted from higher electrode spacings are believed to be the reason for more COD and nitrogen removals [23,27]. This also means 
that probably a portion of the COD content and the nitrogen content in the SBES is removed by (aerobic and anaerobic) processes other than bioelectrochemical ones [28]. These explanations are highly applicable for a brackish water SBES as in this study. Although the electrode spacing tested in this study could not be at the real-life scale (as it was not feasible to make a $1.3 \mathrm{~m}$ deep water column with the same dimensional ratio in the laboratory), it can be deduced that if the SBES is applied in practice the effect of changing the electrode spacing should be similar.

While changing the external resistance and the electrode spacing could significantly affect the performance of the SBES relative to natural degradation at various degrees, changing the temperature had little effect, which is quite surprising. Our results suggest that only within the optimal temperature range of $25-30^{\circ} \mathrm{C}$, the bioelectrochemical processes are the most robust and slightly outcompete natural degradation processes. At the temperatures that were too low, the SBES could not perform its bioremediation as well as natural degradation. Indeed, poorer performances at lower temperatures were also reported for other BESs [1, 14, 15, 23] and optimal temperatures of $32^{\circ} \mathrm{C}$ [14], or $35^{\circ} \mathrm{C}$ [15], or $28-30^{\circ} \mathrm{C}$ [1], which were close to those in this study, were suggested. However, the poorer performance of the SBES in this study (compared to the control) at high temperatures, e.g. $35^{\circ} \mathrm{C}$ or $40^{\circ} \mathrm{C}$, was unpredictable. Probably, under brackish conditions, such high temperatures can accelerate natural degradation more than they can do to the electrochemical processes in the SBES. This has not been reported before because in other studies, the performances of investigated systems were compared with those of themselves at different temperatures, not with those of the control as in this study. Thus, a thorough performance comparison between the SBES and the control as conducted in this study allows more profound understanding of the effect of operational parameters, including temperature. The narrow optimal temperature range $\left(25-30^{\circ} \mathrm{C}\right)$ for the SBES in this study also implies that the optimal temperature range for electrochemically active bacteria under brackish conditions is narrower than that for all bacteria in the pond sediment. In our previous study, we found that the bacterial communnity in the sediment of our brackish SBES was distinct, i.e. it was dominated by some unique bacteria such as Methylophilus rhizosphaerae, Thiothrix eikelboomii and Desulfatitalea tepidiphila, which had not been previously reported in other BESs [3]. Among those species, Methylophilus rhizosphaerae and Thiothrix eikelboomii were reported to grow optimally at temperatures ranging from $28-30^{\circ} \mathrm{C}[29,30]$. Probably, these species play more important roles in the bioelectrochemical performance of the SBES and thus decide its optimal temperature range.

Like the effect of ambient temperature, the effect of salinity on the performance of the SBES (in relation to the control) is rather unpredictable. For brackish systems, salinity should be considered as a very important operation-affecting factor. However, little has been known about its effect on the performance of SBESs. Sajana et al. studied a freshwater system and thus did not investigated the effect of salinity [1, 23]. Hong et al. [15] did not directly investigate the effect of salinity on the power generation of a SMFC but the effect of conductivity, which is closely linked to salinity. According to that, increasing the conductivity of the SBES water to $20,000 \mu \mathrm{S} \mathrm{cm}^{-1}$ and $50,000 \mu \mathrm{S} \mathrm{cm}^{-1}$ could lead to proportionally increased current densities, due to lowered internal resistances. However, it is not clear which levels of salinity can be equivalent to those levels of conductivity. In this study, the current density increased when the salinity increased up to $1.5 \%$ and decreased when the latter increased further. Mohan et al. [31] also observed in a MFC system that the current increased when the concentration of $\mathrm{NaCl}$ increased up to $10 \mathrm{mM}$ and decreased when the latter increased further. These similar responses suggest that salinity can only boost the electricity generation of a SBES to a certain limit. Probably in Hong et al.'s study [15], if the conductivity could have further increased, the current density would have been reduced. Furthermore, it should be mentioned that the effect of salinity is not exclusively linked with conductivity but also related to other aspects such as osmotic pressure and/or toxicity of ions to microorganisms [32, 33]. Nevertheless, the reason for the effect of salinity on electricity generation is actually not too important as the electricity generation was not closely linked to the performance of the SBES in removing COD and nitrogen. It is difficult to explain why the SBES removed the sediment COD more efficiently than the control when the salinity was $1.5 \% \pm 0.5 \%$ while it did not do better to water COD. It is plausible that the electrochemically active bacteria at the sediment work better in that salinity range and thus they convert the nearby sediment COD more efficiently but they can not act better on water COD due to mass transfer limit [6]. Those COD removal results, together with the electricity generation results, suggest that the enriched bacteria at the sediment electrode of the SBES are more adapted to the enrichment salinity, which is $1.5 \%$. This also implies that 
they can be vulnerably affected if the salinity is greatly changed. Such a great change in salinity may inhibit the electrochemical activity of the bacteria and also shift their metabolism. Such a metabolic shift might be so much and unique when the salinity increased to $2.5 \%$ that the bacteria could ultimately utilize nitrogen (including ammonium) in the water much more efficiently than those performing natural degradation (in the control). The mechanism for this is unclear but it was reported that salinity could affect the $\mathrm{NH}_{4}{ }^{+} / \mathrm{NH}_{3}$ fraction in seawater [34], thereby affecting the bioavailability of ammonium-nitrogen to nitrifying bacteria. Indeed, nitrification rate could increase when salinity increased to a certain level such as $20 \mathrm{ppt}$ [35]. In this study, $2.5 \%$ is probably the optimal salinity level for the bacteria enriched under electrochemical conditions to access ammonium and carry out nitrification independent from electricity generation. At that salinity, these bacteria seem to perform (non-bioelectrochemical ammonium oxidation) much better than the natural ones, as demonstrated by the water nitrogen removing effciency difference results (Figs. 6B and 6C).

In addition to temperature and salinity, $\mathrm{pH}$ of the pond water is another environmental factor that is not controllable. The effect of the $\mathrm{pH}$ on the performance of the SBES in this study was notably different from those in most of previous relevant studies. In terms of electricity generation, the SBES generated higher currents at both the low $\mathrm{pH}$ of 5.5 and the high $\mathrm{pH}$ of 8.8 than at $\mathrm{pH} 7$, while it was reported by several studies that power generation is generally proportional to the $\mathrm{pH}[10,23]$. Only Jang et al. (2004) reported that acidifying the water of a membraneless MFC (actually similar to a SBES), thereby reducing the $\mathrm{pH}$, could increase the electrical current due to a better cathode reaction [6]. Indeed, in our study the low $\mathrm{pH}$ of 5.5 also resulted in better ammonium removing performance of our brackish SBES compared to that of the control (natural degradation). Possibly, a low $\mathrm{pH}$ increases the ionization of ammonium-nitrogen and makes it more accessible for the anodic bacteria to oxidize [34]. Thus at low $\mathrm{pHs}$, ammonium removal can be considered to be coupled with electricity generation. However, regarding $\mathrm{COD}$ and total nitrogen removals, $\mathrm{pH} 7$ generally appeared to be more optimal for the SBES, as stated in section 3. This is not consistent with previous observations showing that higher COD removals by BESs could be achieved with lower $\mathrm{pHs}[23,36]$ and that higher $\mathrm{pHs}($ e.g. 8.5) resulted in higher total nitrogen removals by the SBES [1,23]. The fact that the extreme pHs (5.5 and 8.8) favored electricity generation while $\mathrm{pH} 7$ favored COD and total nitrogen removals by the SBES again leads to a deduction that COD and nitrogen removals are not fully linked to electricity generation. This is similar to what was observed in the experiments testing the effects of other parameters (as discussed above) and therefore again supports the hypothesis that a portion of the COD content and the nitrogen content in the SBES is removed by processes other than bioelectrochemical ones. In principle, neutral $\mathrm{pHs}$ of around 7 is optimal for most bacteria [37] and this rule is probably true for the non-electroactive bacteria that might be partially responsile for COD and nitrogen removals but does not seem applicable for the electrochemically active bacteria in the brackish SBES. It is unclear why that is but it is possible that under brackish conditions, the enriched electroactive bacteria respond to $\mathrm{pH}$ changes differently from those in freshwater, or $\mathrm{pH}$ changes might cause different physiochemical processes.

It should be noted that all the responses of the systems to changes of the operational parameters discussed above are reliable, as the experiments were replicated 3 times. In addition, a similar test tank set up as a back-up system in our study also had similar responses in all experiments (data not shown).

\section{General Points to Consider}

The results altogether suggest that electricity generation by the brackish water SBES is not fully linked to its COD removal and nitrogen removal. However, the degrees of unlinkedness are not the same for all the latters: electricity generation seems to be linked more closely to COD removal but less closely to nitrogen removal. Indeed, this is reasonable as the oxidation of organic matter is the main process to provide electrons to be transferred to the anode $[5,6]$. Indeed, in a freshwater SBES, it was also observed that COD removal and nitrogen removal were not fully linked to electricity generation [23]. Depending on the condition, the link of electricity generation may be more close to COD removal or to nitrogen removal $[17,23]$. As discussed earlier, this unlinkedness indicates that the removals of COD and especially nitrogen in a pond even containing a SBES are under certain conditions not solely due to bioelectrochemical processes. Natural nonbioelectrochemical processes may partially play some roles in removing these components and contribute to the overall removal performance of the system. However, the nitrogen- or ammonium-removing efficiency differences between the SBES-containing tank and the control under some conditions not favoring electricity generation (such $2.5 \%$ salinity) suggest that the electrochemically enriched 
bacteria can still remove nitrogen better under those conditions. Indeed, when electron transfer to the anodic electrode is inhibited, competing processes such as denitrification might have chance to occur at higher rates, thereby enabling complete nitrogen removal. It is highly possible that the electrochemically enriched bacteria in the SBES, the dominant species of which can reduce nitrate [3], can shift their electron acceptor from the electrode to nitrate under such electrochemically unfavored conditions.

It should be emphasized that in this study we evaluated the performances of the brackish water SBES, in terms of electricity generation, COD removal and nitrogen removal, always in comparison with those of the control. i.e. natural degradation. Such an approach can ensure that the data obtained are practically meaningful as they reflect the true differences in the performances of the SBES versus natural degradation under different operational conditions in reality. This is dissimilar to the approaches of other previous studies focusing on comparing the performance of a system with those of itself just at varied levels of one condition. Assuming that a SBES performs better under a condition than itself under other conditions but if natural degradation performs even much better under that condition, then in fact it is not certain to tell whether the performance of the SBES is practically better. This consideration is particularly important when the research aim is to evaluate the potential of applying the SBES for bioremediation of brackish aquaculture ponds in reality.

\section{Proposed Practices for More Efficient Bioremediation If Applying the SBES in Brackish Water Aquaculture in Reality}

First of all, it is easy to realize that if the SBES is to be applied in practice, ones can proactively manipulate the controllable factors such as external resistance or electrode spacing to maximize the bioremediation. Depending on the bioremediation priority, ones can adjust the parameters accordingly. For instance, if the priority is to remove COD, it is probably more appropriate to operate the SBES with an external resistance of around $100 \Omega$. However, if nitrogen removal is more important, adjusting the external resistance to higher levels, such as $188 \Omega$, may further improve the nitrogen removal efficiency of the system. Ones can also consider to increase the electrode spacing in order to achieve more COD and nitrogen removals with the SBES. It may be more difficult to achieve that under real-life conditions, due to standard sizes of aquaculture ponds [38]. Nevertheless, this factor can be taken into account when designing a pond and the integrated SBES prior to farming.

Regarding the uncontrollable factors including temperature, salinity and $\mathrm{pH}$, the results of this study suggest some actions to be done in response to changes of these parameters. As for temperature, in tropical areas (such as the south of Vietnam), this factor can be within the optimal range for SBES and less varied and thus little should be done to prevent its negative effects. However, in temperate or subtropical zones, the ambient temperature can be fluctuating within a large amplitude and thus proper measures should be applied to prevent its effects. As mentioned above, high temperatures $\left(35-40^{\circ} \mathrm{C}\right)$ may not be a big issue as they may also accelerate natural removals of COD and particularly nitrogen, but low temperatures (less than $25^{\circ} \mathrm{C}$ ) may slow down both bioelectrochemical removals and natural removals. Thus proper warming solutions should be considered for the ponds operated in the areas where temperature can drop down. Indeed, solar heating systems can be used as an economic solution for this purpose [39]. However, this may not be sufficient when the other uncontrollable factors, the salinity and the $\mathrm{pH}$ of the water, also vary due to seasonal changes. For example, in tropical regions, during the dry season, the salinity and the $\mathrm{pH}$ of the pond water may significantly increase while during the rainy season, they may decrease due to more dilution. As mentioned above, neutral $\mathrm{pHs}$ are better for COD and nitrogen removals by the SBES; thus when the $\mathrm{pH}$ changes, it is essential to have countermeasures to adjust it back. Also, countermeasures to environmental changes should include those to keep the water salinity around $1.5 \%$ if one wants an optimal COD removal by the SBES. Indeed, in real-life aquaculture, it is actually difficult to have such feasible countermeasures because of the huge volume and superlarge areas of farming. Probably, the more realistic response is to carry out additional treatments of COD and nitrogen of the pond water when the removals by the SBES are not efficient enough under unfavorable conditions. The only serendipity one can expect without additional actions is the more efficient removal of nitrogen in the pond water when the salinity increases to higher than $2.0 \%$, especially when nitrogen removal is a priority.

Last but not least, it should also be considered that reallife applications or larger scale applications will face largescale challenges, such as significant reduced power, and thus will require additional approaches to maintain an efficient performance of a BES [40]. Furthermore, long-term 
operations of such SBES in practical aquaculture certainly lead to declined performance due to biofilm growth on the cathode [41, 42]. Indeed, with our laboratory-scale system, we observed a relatively stable open circuit voltage of the SBES, which was around $250 \mathrm{mV}$, but it slightly decreased to around $230 \mathrm{mV}$ after one year of operation, together with an approximately $20 \%$ decrease in the power of the SBES. This is possibly a result of a biofilm-like thin layer that could be observed on the cathode surface. Therefore, appropriate solutions, such as using magnets, to reduce biofilm growth on the cathode should be also paid attention to when applying the SBES at large scales [43].

In summary, in this study, the effects of several controllable and uncontrollable operational parameters on the performance of a sediment bioelectrochemical system (SBES) integrated in a brackish aquaculture pond model were thoroughly inspected with a practical view by comparing them to those on the performance of a natural degradation control model. While the effects of external resistance and electrode spacing could be considered similar to those reported previously for other systems, the effect of temperature, salinity and $\mathrm{pH}$ of the pond water were relatively unpredictable and demonstrated distinct responses of the SBES when operated under brackish conditions. Although those responses imply that the removals of COD and nitrogen in the systems are not fully linked to bioelectrochemical processes, the more efficient performance of the SBES versus the control in general confirms the application potential of the SBES in brackish aquaculture bioremediation. Furthermore, the results of this study provides a background to propose efficient practices to warrant the success of such application in reallife scenarios.

\section{Acknowledgments}

This research is funded by Vietnam National Foundation for Science and Technology Development (NAFOSTED) under grant number 106-NN.04-2015.23. The authors would like to deeply thank Prof Te Quang Bui from Research Institute for Aquaculture No.1, Bac Ninh, Vietnam for his valuable comments and information sharing.

\section{Conflicts of Interest}

The authors have no financial conflicts of interest to declare.

\section{References}

1. Sajana TK, Ghangrekar MM, Mitra A. 2013. Application of sediment microbial fuel cell for in situ reclamation of aquaculture pond water quality. Aquacultural Eng. 57: 101107.

2. Boyd CE. 1998. Pond water aeration systems. Aquacultural Eng. 18: 9-40.

3. Pham TH, Tran TH, Vu TL, Dang TH, Nguyen TTT, Dang THT, et al. 2019. A laboratory-scale study of the applicability of a halophilic sediment bioelectrochemical system for in situ reclamation of water and sediment in brackish aquaculture ponds: establishment, bacterial community and performance evaluation. J. Microbiol. Biotechnol. 29: 1104-1116.

4. Reimers CE, Tender LM, Fertig S, Wang W. 2001. Harvesting energy from the marine sediment-water interface. Environ. Sci. Technol. 35: 192-195.

5. Bond DR, Holmes DE, Tender LM, Lovley DR. 2002. Electrode-reducing microorganisms that harvest energy from marine sediments. Science 295: 483-485.

6. Jang JK, Pham TH, Chang IS, Kang KH, Moon H, Cho KS, et al. 2004. Construction and operation of a novel mediatorand membrane-less microbial fuel cell. Process Biochem. 39: 1007-1012.

7. Lovley DR. 2006. Bug juice: harvesting electricity with microorganisms. Nat. Rev. Microbiol. 4: 497-508.

8. Kim BH, Chang IS, Gadd GM. 2007. Challenges in microbial fuel cell development and operation. Appl. Microbiol. Biotechnol. 76: 485-494.

9. Venkata Mohan S, Velvizhi G, Annie Modestra J, Srikanth S. 2014. Microbial fuel cell: critical factors regulating biocatalyzed electrochemical process and recent advancements. Renewable Sustainable Energy Rev. 40: 779-797.

10. Gil G-C, In-Seop C, Byung Hong K, Mia K, Jae-Kyung J, Hyung Soo $\mathrm{P}$, et al. 2003. Operational parameters affecting the performance of a mediator-less microbial fuel cell. Biosens. Bioelectron. 18: 327-334.

11. Pham TH, Aelterman P, Verstraete W. 2009. Bioanode performance in bioelectrochemical systems: recent improvements and prospects. Trends Biotechnol. 27: 168-178.

12. Scott K, Cotlarciuc I, Hall D, Lakeman JB, Browning D. 2008. Power from marine sediment fuel cells: the influence of anode material. J. Appl. Electrochem. 38: 1313-1319.

13. Scott K, Cotlarciuc I, Head I, Katuri KP, Hall D, Lakeman JB, et al. 2008. Fuel cell power generation from marine sediments: investigation of cathode materials. J. Chem. Technol. Biotechnol. 83: 1244-1254.

14. Liu H, Cheng SA, Logan BE. 2005. Power generation in fedbatch microbial fuel cells as a function of ionic strength, temperature, and reactor configuration. Environ. Sci. Technol. 39: 5488-5493.

15. Hong SW, Chang IS, Choi YS, Chung TH. 2009. Experimental evaluation of influential factors for electricity harvesting 
from sediment using microbial fuel cell. Bioresour. Technol. 100: 3029-3035.

16. He Z, Huang Y, Manohar AK, Mansfeld F. 2008. Effect of electrolyte $\mathrm{pH}$ on the rate of the anodic and cathodic reactions in an air-cathode microbial fuel cell. Bioelectrochemistry 74: 78-82.

17. Sajana TK, Ghangrekar MM, Mitra A. 2013. Effect of $\mathrm{pH}$ and distance between electrodes on the performance of a sediment microbial fuel cell. Water Sci. Technol. 68: 537-543.

18. Aelterman P, Rabaey K, Pham HT, Boon N, Verstraete W. 2006. Continuous electricity generation at high voltages and currents using stacked microbial fuel cells. Environ. Sci. Technol. 40: 3388-3394.

19. Logan BE, Hamelers B, Rozendal R, Schrorder U, Keller J, Freguia S, et al. 2006. Microbial fuel cells: Methodology and technology. Environ. Sci. Technol. 40: 5181-5192.

20. Logan BE. 2008. Microbial fuel cells, pp. 54-55. Ed. John Wiley \& Sons.

21. Greenberg A, Clesceri LS, Eaton AD. 1992. Standard Methods for the Examination of Water and Wastewater, 18th Edn, pp. 5-16. Ed. American public health association, Washington.

22. Vyrides I, Stuckey D. 2009. A modified method for the determination of chemical oxygen demand (COD) for samples with high salinity and low organics. Bioresour. Technol. 100: 979-982.

23. Sajana TK, Ghangrekar MM, Mitra A. 2014. Effect of operating parameters on the performance of sediment microbial fuel cell treating aquaculture water. Aquac. Eng. 61: 17-26.

24. Menicucci J, Beyenal H, Marsili E, Veluchamy RA, Demir G, Lewandowski Z. 2006. Procedure for determining maximum sustainable power generated by microbial fuel cells. Environ. Sci. Technol. 40: 1062-1068.

25. Song S-H, Yeom S-H, Choi S-S, Yoo Y-J. 2003. Effect of oxidation-reduction potential on denitrification by Ochrobactrum anthropi SY509. J. Microbiol. Biotechnol. 13: 473-476.

26. Viet TN, Behera SK, Kim JW, Park H-S. 2008. Effects of oxidation reduction potential and organic compounds on anammox reaction in batch cultures. Environ. Eng. Res. 13: 210-215.

27. Zhang X, Zhu F, Chen L, Zhao Q, Tao G. 2013. Removal of ammonia nitrogen from wastewater using an aerobic cathode microbial fuel cell. Bioresour. Technol. 146: 161-168.

28. González del Campo A, Cañizares P, Lobato J, Rodrigo M, Fernandez Morales FJ. 2016. Effects of External Resistance on Microbial Fuel Cell's Performance, pp. 175-197. In Lefebvre G, Jiménez E, Cabañas B (eds.), Environment, Energy and Climate Change II: Energies from New Resources and the Climate Change, Ed. Springer International Publishing, Cham
29. Doronina NV, Gogleva AA, Trotsenko YA. 2012. Methylophilus glucosoxydans sp. nov., a restricted facultative methylotroph from rice rhizosphere. Int. J. Syst. Evol. Microbiol. 62: 196-201.

30. Aruga S, Kamagata Y, Kohno T, Hanada S, Nakamura K, Kanagawa T. 2002. Characterization of filamentous Eikelboom type $021 \mathrm{~N}$ bacteria and description of Thiothrix disciformis sp. nov. and Thiothrix flexilis sp. nov. Int. J. Syst. Evol. Microbiol. 52: 1309-1316.

31. Mohan Y, Das D. 2009. Effect of ionic strength, cation exchanger and inoculum age on the performance of Microbial Fuel Cells. Int. J. Hydrogen Energy 34: 7542-7546.

32. Chen Y, Cheng JJ, Creamer KS. 2008. Inhibition of anaerobic digestion process: a review. Bioresour. Technol. 99: 4044-4064.

33. Yan N, Marschner P, Cao W, Zuo C, Qin W. 2015. Influence of salinity and water content on soil microorganisms. Int. Soil Water Conservation Res. 3: 316-323.

34. Bower CE, Bidwell JP. 1978. Ionization of ammonia in seawater: effects of temperature, $\mathrm{pH}$, and salinity. J. Fisheries Res. Board Canada 35: 1012-1016.

35. Isnansetyo A, Getsu SAI, Seguchi M, Koriyama M. 2014. Independent effects of temperature, salinity, ammonium concentration and $\mathrm{pH}$ on nitrification rate of the ariake seawater above mud sediment. HAYATI J. Biosci. 21: 21-30.

36. Zhang L, Li C, Ding L, Xu K, Ren H. 2011. Influences of initial $\mathrm{pH}$ on performance and anodic microbes of fed-batch microbial fuel cells. J Chem. Technol. Biotechnol. 86: 12261232.

37. Madigan MT, Bender KS, Buckley DH, Sattley WM, Stahl DA. 2019. Brock Biology of Microorganisms, $15^{\text {th }}$ Ed., pp. 188189. Ed. Pearson Education Inc., NJ.

38. Boyd CE, Schmittou HR. 1999. Achievement of sustainable aquaculture through environmental management. Aquac. Economics Manag. 3: 59-69.

39. Fuller RJ. 2007. Solar heating systems for recirculation aquaculture. Aquac. Eng. 36: 250-260.

40. Rossi R, Jones D, Myung J, Zikmund E, Yang W, Gallego YA, et al. 2019. Evaluating a multi-panel air cathode through electrochemical and biotic tests. Water Res. 148: 51-59.

41. Yang W, Rossi R, Tian Y, Kim K-Y, Logan BE. 2018. Mitigating external and internal cathode fouling using a polymer bonded separator in microbial fuel cells. Bioresour. Technol. 249: 1080-1084.

42. Zhang F, Pant D, Logan BE. 2011. Long-term performance of activated carbon air cathodes with different diffusion layer porosities in microbial fuel cells. Biosens. Bioelectron. 30: 49-55.

43. Rossi R, Yang W, Zikmund E, Pant D, Logan BE. 2018. In situ biofilm removal from air cathodes in microbial fuel cells treating domestic wastewater. Bioresour. Technol. 265: 200-206. 